\title{
How Should We Revise Diagnostic Criteria for Substance Use Disorders in the $D S M-V$ ?
}

\author{
Christopher S. Martin and Tammy Chung \\ University of Pittsburgh School of Medicine
}

\author{
James W. Langenbucher \\ Rutgers University
}

\begin{abstract}
This article reviews literature on the validity and performance characteristics of the Diagnostic and Statistical Manual of Mental Disorders (4th ed.; DSM-IV; American Psychiatric Association, 1994) diagnostic criteria for substance use disorders (SUDs) and recommends changes in these criteria that should be considered for the next edition of the DSM $(D S M-V)$. Substantial data indicate that DSM-IV substance abuse and substance dependence are not distinct categories and that SUD criteria are best modeled as reflecting a unidimensional continuum of substance-problem severity. The conceptually and empirically problematic substance abuse diagnosis should be abandoned in the $D S M-V$, with substance dependence defined by a single set of criteria. Data also indicate that various individual SUD criteria should be revised, dropped, or considered for inclusion in the $D S M-V$. The $D S M-V$ should provide a framework that allows the integration of categorical and dimensional approaches to diagnosis. Important areas for further research are noted.
\end{abstract}

Keywords: substance use disorders, diagnostic criteria, DSM-IV, DSM-V

Since the publication of the fourth edition of the Diagnostic and Statistical Manual of Mental Disorders (DSM-IV; American Psychiatric Association, 1994), a substantial amount of research has examined the validity and performance of this manual's diagnostic criteria for substance use disorders (SUDs) in adults and adolescents. This article reviews this literature and recommends revisions to SUD diagnostic criteria that should be considered for the fifth edition of the DSM (DSM-V; Kupfer, First, \& Regier, 2002; Schuckit \& Saunders, 2006). In many cases, extant data on problems with the DSM-IV criteria point toward specific recommendations for the $D S M-V$. In other cases, we describe limitations and issues related to the $D S M-I V$ criteria that require additional consideration and study, such as in the nosologically informative data sets described by Cottler and Grant (2006). We expect that some of these topics will be controversial and that alternate views will be expressed. We welcome this dialogue and hope that our recommendations will generate discussion and research that will inform the $D S M-V$ development process. It is important for the field to consider these issues now, given the planned timeline of 2012 for the publication of the new manual.

This article has four main sections. The introduction discusses conceptual issues in the meaning of the term mental disorder,

Christopher S. Martin and Tammy Chung, Western Psychiatric Institute and Clinic, Department of Psychiatry, University of Pittsburgh School of Medicine; James W. Langenbucher, Center of Alcohol Studies, Rutgers University.

This research was supported by National Institute on Alcohol Abuse and Alcoholism Grants R01 13397 and K02 00249 to Christopher S. Martin, K01 00324 and R01 014357 to Tammy Chung, and by National Institute on Drug Abuse Grant K02 00390 to James W. Langenbucher.

Correspondence concerning this article should be addressed to Christopher S. Martin, Western Psychiatric Institute and Clinic, University of Pittsburgh School of Medicine, 3811 O'Hara Street, Pittsburgh, PA 15213. E-mail: martincs@upmc.edu provides a historical overview of $D S M$ criteria for SUDs, and describes symptoms and diagnostic algorithms in the DSM-IV. The second section describes conceptual and empirical problems in the definitions of and diagnostic algorithms for substance abuse and substance dependence, as well as proposed solutions for the $D S M-V$. The third section describes important limitations of a number of individual DSM-IV SUD criteria and makes recommendations for revising, dropping, and adding criteria for the $D S M-V$. In the fourth section, we propose ways in which the $D S M-V$ should integrate categorical and dimensional approaches to diagnosis. To provide a roadmap for the article, Table 1 summarizes the primary problems we identify in the DSM-IV criteria and potential solutions to consider for the $D S M-V$. Each of the topics summarized in Table 1 is elaborated in the text.

It is not possible to comprehensively address all potential areas of revising the DSM-IV SUD criteria in a single article. Instead, we discuss those topics that we see as particularly important. We emphasize SUDs for psychoactive drugs as defined in the DSM-IV and do not focus on important areas, such as pathological gambling, that can be considered, in some senses, to be addictive disorders (Petry, 2006; Potenza, 2006). We also do not address diagnostic criteria in the International Classification of Diseases, Volume 10 (ICD-10; World Health Organization, 1992) or the ICD-11 development process (Hasin, Hatzenbuehler, Keyes, \& Ogburn, 2006; Saunders, 2006). We also do not detail remission criteria for substance dependence or the possible development of drug-specific diagnostic algorithms (Hughes, 2006).

\section{Mental Disorder as Harmful Dysfunction}

Mental disorders can be described as evolving constructs that serve to describe and organize a constellation of associated pathological signs and symptoms (Kendall, 1975; Millon, 1991), with the goal of describing meaningful types to guide research and clinical practice (Robins \& Guze, 1970; Widiger \& Clark, 2000). 
Table 1

Problems Identified in the DSM-IV Substance Use Disorder (SUD) Criteria and Proposed Solutions

\begin{tabular}{|c|c|}
\hline Problems with $D S M-I V$ criteria & Solutions to consider for the $D S M-V$ \\
\hline $\begin{array}{l}\text { 1. The substance abuse diagnosis does not have a clear conceptual } \\
\text { core and does not meet standards for the concept of mental disorder. } \\
\text { Abuse has multiple divergent meanings. }\end{array}$ & $\begin{array}{l}\text { 1. Abandon the category of substance abuse. Define a single category } \\
\text { of substance dependence using revised } D S M-I V \text { SUD criteria and new } \\
\text { symptoms, such as a consumption criterion. }\end{array}$ \\
\hline $\begin{array}{l}\text { 2. Lack of empirical distinctions between the } D S M-I V \text { 's mutually } \\
\text { exclusive criteria for substance abuse and dependence. }\end{array}$ & $\begin{array}{l}\text { 2. Define SUDs in the } D S M-V \text { using a combined criterion set, } \\
\text { reflecting evidence for a unidimensional continuum of substance } \\
\text { problems. }\end{array}$ \\
\hline $\begin{array}{l}\text { 3. The } D S M-I V \text { diagnostic algorithms produce unequal diagnostic } \\
\text { coverage of those with similar levels of substance-problem severity } \\
\text { and make rates of disorders highly sensitive to variation in the } \\
\text { observed prevalence of individual criteria. }\end{array}$ & $\begin{array}{l}\text { 3. Define SUDs in the } D S M-V \text { using a single combined criterion set. } \\
\text { Avoid low thresholds for diagnosis to make algorithms more robust to } \\
\text { variation in the prevalence of individual criteria. }\end{array}$ \\
\hline $\begin{array}{l}\text { 4. The } D S M-I V \text { 's change-based definition of tolerance can be assigned } \\
\text { to those with relatively low levels of substance use. }\end{array}$ & $\begin{array}{l}\text { 4. Revise the definition of tolerance to require a minimum level of use } \\
\text { in addition to the change-based definition. }\end{array}$ \\
\hline $\begin{array}{l}\text { 5. DSM-IV abuse and dependence are defined by a maladaptive } \\
\text { pattern of use, but actual substance use patterns are not described or } \\
\text { used as a diagnostic criterion. }\end{array}$ & $\begin{array}{l}\text { 5. Incorporate a consumption criterion, such as } 5+(\text { men) and } 4+ \\
\text { (women) U.S. standard drinks within } 2 \mathrm{hr} \text { at least once/week for } \\
\text { alcohol and any use at least once/week for other drugs. }\end{array}$ \\
\hline $\begin{array}{l}\text { 6. The physiologic features subtype is defined as withdrawal or } \\
\text { tolerance, but only the former predicts clinical course. }\end{array}$ & $\begin{array}{l}\text { 6. Define the physiologic features subtype of substance dependence by } \\
\text { withdrawal only. }\end{array}$ \\
\hline $\begin{array}{l}\text { 7. The threshold of } 2 \text { of } 8 \text { subcriteria for alcohol withdrawal is } \\
\text { vulnerable to false positive assignments, especially in community } \\
\text { samples. }\end{array}$ & $\begin{array}{l}\text { 7. Emphasize specificity over sensitivity by removing mild alcohol } \\
\text { withdrawal subcriteria, such as anxiety and vomiting, and/or increase } \\
\text { the threshold for symptom assignment. }\end{array}$ \\
\hline $\begin{array}{l}\text { 8. There is good evidence for a cannabis withdrawal syndrome, but } \\
\text { cannabis withdrawal is not an SUD symptom in the } D S M-I V \text {. }\end{array}$ & $\begin{array}{l}\text { 8. Cannabis withdrawal should be a diagnostic criterion in the } D S M-V \text {. } \\
\text { Research is needed to test subcriteria and subalgorithms. }\end{array}$ \\
\hline $\begin{array}{l}\text { 9. The larger/longer symptom can lead to false positive symptom } \\
\text { assignments among those who do not report a compulsive pattern of } \\
\text { substance use. }\end{array}$ & $\begin{array}{l}\text { 9. The } D S M-V \text { (and associated measures) should clarify that using more } \\
\text { or longer occurs due to compulsive use and not merely social reasons. }\end{array}$ \\
\hline $\begin{array}{l}\text { 10. Quit/cut down is defined by persistent desire or repeated attempts to } \\
\text { quit or cut down use; the former is a far less severe problem } \\
\text { indicator. }\end{array}$ & $\begin{array}{l}\text { 10. Consider splitting the criterion into two separate criteria to better } \\
\text { scale the range of substance problems. }\end{array}$ \\
\hline $\begin{array}{l}\text { 11. Hazardous use and legal problems poorly discriminate substance- } \\
\text { problem severity, show gender bias, and are influenced by cultural } \\
\text { differences and secular trends. }\end{array}$ & $\begin{array}{l}\text { 11. These symptoms should be removed as diagnostic criteria for SUDs. } \\
\text { Substance-related illegal behavior should remain as a criterion for } \\
\text { antisocial disorders. }\end{array}$ \\
\hline $\begin{array}{l}\text { 12. SUD symptoms oversample moderate levels of pathology and are } \\
\text { less accurate in scaling mild and severe levels of substance problems. }\end{array}$ & $\begin{array}{l}\text { 12. Consider including criteria that may measure mild or severe } \\
\text { manifestations of substance problems, such as a consumption criterion, } \\
\text { craving, and rapid reinstatement. }\end{array}$ \\
\hline $\begin{array}{l}\text { 13. The } D S M-I V \text { is largely categorical and does not elaborate a } \\
\text { framework for integrating dimensional approaches to diagnosis. }\end{array}$ & $\begin{array}{l}\text { 13. The } D S M-V \text { should integrate categorical and dimensional approaches } \\
\text { to diagnosis, with attention to subdiagnostic manifestation of } \\
\text { symptoms and SUDs, scaling the severity of SUDs, and describing } \\
\text { noncriterion features. }\end{array}$ \\
\hline $\begin{array}{l}\text { 14. The comorbidity and shared underlying risk factors of SUDs with } \\
\text { other externalizing disorders, such as CD and ASPD, are not well } \\
\text { represented in the structure and description of DSM-IV diagnostic } \\
\text { groupings. }\end{array}$ & $\begin{array}{l}\text { 14. The } D S M-V \text { should group SUDs with an externalizing spectrum of } \\
\text { psychopathology that includes CD and ASPD. The text of this chapter } \\
\text { of the manual should highlight the associations among and shared risk } \\
\text { factors underlying externalizing syndromes. }\end{array}$ \\
\hline
\end{tabular}

Note. $\quad$ DSM-IV = Diagnostic and Statistical Manual of Mental Disorders (4th ed.; American Psychiatric Association, 1994); DSM-V = Diagnostic and Statistical Manual of Mental Disorders (5th ed., to be published); CD = conduct disorder; ASPD = antisocial personality disorder.

There has been considerable discussion of the fundamental issue of the definition of pathology, that is, what constitutes a mental disorder. The text revision of the DSM-IV (American Psychiatric Association, 2000, pp. xxx-xxxi) states that although no single definition is adequate, mental disorders can be considered clinically significant behavioral or psychological syndromes that are associated with distress and impairment, are not merely an expectable reaction to a particular event, and are considered a manifestation of some underlying dysfunction in the individual. Wakefield (1992, 1999) elaborated these concepts and defined disorder as the failure of an internal mechanism to perform its naturally selected evolutionary function, causing harm to an individual. Although there are differences between these two approaches, they share important features (Wakefield \& First, 2003). Each emphasizes that disorder is an attribute of an individual in which something has gone wrong in the functioning of an internal mechanism
(Spitzer \& Endicott, 1978). Each excludes dysfunction that does not cause sufficient harm or distress. Each excludes distress that is not caused by dysfunction but instead by social deviance or conflict with society.

\section{Evaluating SUD Criteria and Diagnoses in the Context of Harmful Dysfunction}

It is important to evaluate diagnostic criteria for SUDs in the context of conceptual issues related to the definition of mental disorder. If substance problems do not reflect underlying dysfunction in an internal mechanism and instead merely indicate foolhardiness or poor judgment, this should not be sufficient to constitute a disorder. On the other hand, there is substantial evidence that those with SUDs often do have significant dysfunction in internal mechanisms. A prominent example is that many theories 
Table 2

Substance Abuse and Dependence Symptoms in the DSM-IV

\begin{tabular}{|c|c|}
\hline Brief symptom descriptor & Abstracted $D S M-I V$ definition \\
\hline \multicolumn{2}{|l|}{ Abuse symptoms } \\
\hline Role impairment & Frequent intoxication leading to a failure to fulfill major role obligations \\
\hline Hazardous use & Recurrent use when it is physically hazardous (e.g., drunk driving) \\
\hline Legal problems & Recurrent substance-related legal problems \\
\hline Social problems & Continued use despite social or interpersonal problems caused or exacerbated by use \\
\hline \multicolumn{2}{|l|}{ Dependence symptoms } \\
\hline Tolerance & Need to consume more to achieve same effect; decreased effect with same amount \\
\hline Withdrawal & Signs of withdrawal syndrome; use to avoid withdrawal \\
\hline Larger/longer & Often using more or for a longer period than intended \\
\hline Quit/cut down & Persistent desire or unsuccessful attempts to quit or cut down substance use \\
\hline Much time spent using & Lots of time spent using, obtaining, or being affected by a substance \\
\hline Reduced activities & Important social activities given up or reduced due to substance use \\
\hline Psychological/physical problems & Continued use despite psychological/physical problems caused or exacerbated by use \\
\hline
\end{tabular}

Note. Abuse is diagnosed when at least one of the four abuse criteria are present, and dependence is diagnosed when at least three of the seven dependence criteria occur within the same year. DSM-IV = Diagnostic and Statistical Manual of Mental Disorders (4th ed.; American Psychiatric Association, 1994).

of addiction (e.g., Koob \& Le Moal, 1997; Robinson \& Berridge, 2003; Wise \& Bozarth, 1987) emphasize the centrality of the brain's reward circuitry, which is involved in the critical evolutionary function of appetitive motivation for natural rewards, such as food, water, and sex. Repeated substance use can produce neuroadaptations in this system that "hijack" the brain's reward system and sensitize the incentive salience of substance use, leading to the compulsive patterns of use that are a hallmark of addiction.

\section{Approaches to Classification Prior to the DSM-IV}

The description of alcohol and drug problems, symptoms, and syndromes, largely drawn from experience with clinical samples of adults, has a long history (e.g., Rush, 1787). Jellinek (1943, 1952) described numerous signs and symptoms of alcoholism related to the domains of pathological patterns of use, negative consequences of use, and physiological features, symptoms that were reflected in the Feighner et al. (1972) description of research diagnostic criteria. The third edition of the DSM (DSM-III; American Psychiatric Association, 1980) introduced two categories of SUD: substance abuse, requiring either pathological patterns or negative consequences, and substance dependence, which required one of these domains as well as tolerance or withdrawal. In their description of the alcohol dependence syndrome, Edwards and Gross (1976) eschewed symptoms related to negative consequences that might be culturally or historically bound and emphasized compulsive patterns and the incentive salience of use together with the physiologic features of tolerance and withdrawal. Dependence symptoms in the revised edition of the DSM-III (DSM-III-R; American Psychiatric Association, 1987) largely reflected core features of the alcohol dependence syndrome. Abuse in the $D S M-I I I-R$ was defined by hazardous use or continued use despite consequences; the latter symptom also served as a dependence criterion. Overall, although there has been a good deal of consistency in the description of the addiction constructs that signify SUDs, there also have been substantial changes in how these constructs were moved into and out of the substance abuse category. Each of these previous iterations of the DSM described or implied that abuse was milder than dependence, but in each case, certain symptoms served as criteria for both types of disorder. It was not until the DSM-IV that mutually exclusive criteria were employed, implying more separate factors of substance problems.

\section{$D S M-I V$ SUD Criteria}

$D S M-I V$ criteria for substance abuse and dependence are shown in Table 2. The criteria reflect and often blend a variety of addiction constructs (Hughes, 2007), including tolerance and withdrawal, incentive salience of drug consumption, compulsive patterns of drug use, and negative interpersonal, physical, legal, or social consequences. These criteria apply, in whole or part, to 10 drug classes in addition to an "other" category and the diagnosis of polysubstance dependence (American Psychiatric Association, 1994, 2000). Abuse in the $D S M-I V$ is defined by the presence of at least one of four criteria, and dependence diagnoses require at least three of seven other criteria that cluster within a 1-year period. Dependence is subtyped as with or without "physiologic features," defined by the presence of either tolerance or withdrawal. The abuse and dependence diagnoses are hierarchically arranged, such that any lifetime dependence diagnosis precludes an abuse diagnosis. Withdrawal is not a criterion for cannabis, hallucinogen, phencyclidine, or inhalant dependence, and there is no nicotine abuse category.

\section{SUDs and Diagnostic Algorithms in the DSM-IV and DSM-V}

\section{Conceptual Problems With the DSM-IV's Definition of Substance Abuse}

There is a great deal of conceptual ambiguity in the DSM-IV's definition of substance abuse and the nature of the association between abuse and dependence. Although compulsive use patterns and physiologic features have long been considered core features of dependence, there is no similar accepted conceptual understanding of substance abuse, which has been called a "category without content” (Langenbucher, Martin, Hasin, \& Helzer, 1996, p. 270A) The term abuse has been variously defined by negative social consequences resulting from use, physically or psychologically 
harmful use (World Health Organization, 1992), heedless or hazardous use (Martin, Langenbucher, Kaczynski, \& Chung, 1996), or some combination of these (e.g., American Psychiatric Association, 1980, 1987). Substance abuse diagnoses show very low concordance across iterations of the DSM in adults (B. F. Grant, 1996; Langenbucher, Morgenstern, Labouvie, \& Nathan, 1994) and adolescents (Mikulich, Hall, Whitmore, \& Crowley, 2001; Pollock, Martin, \& Langenbucher, 2000), reflecting dissimilar operational definitions.

Although mutually exclusive, the criterion sets used to diagnose $D S M-I V$ substance abuse and dependence have overlapping conceptual content. Although the DSM-IV SUD workgroup described abuse as reflecting negative social consequences and described dependence in terms of compulsive use and physiologic features (Schuckit, 1994), the situation is far more complex. The abuse symptom of hazardous use reflects risky behavior rather than actual consequences. The interpersonal/social problems symptom is defined by continued use despite consequences, and the role impairment symptom is defined by recurrent intoxication leading to impaired functioning, such that these abuse criteria reflect, in part, the compulsive patterns of use that typify dependence (Babor, 2007). Further, the dependence symptom of reduced social or recreational activities in favor of substance use partly reflects social consequences.

The $D S M-I V$ does not explicitly describe the nature of the relation between these two diagnostic categories. There are only three ways in which abuse can be conceptualized in relation to dependence (Helzer, 1994): (a) as a related but distinct disorder with a separate course, (b) as a residual category defined by criteria that do not load on a dependence factor, or (c) as a mild and frequently prodromal form of dependence. The $D S M-I V$ 's mutually exclusive groups of abuse and dependence symptoms imply distinct factors of substance problems. Yet this is not entirely consistent with the hierarchical decision rule that a diagnosis of dependence precludes abuse, which implies similar illness categories that should differ primarily in severity.

A fundamental conceptual problem is that it is difficult to reconcile the status of $D S M-I V$ substance abuse as a mental disorder with the manual's description of disorders as syndromes that indicate an underlying dysfunction in an internal mechanism rather than as just irresponsible or hazardous behavior. This is especially the case given the disorder's one-symptom threshold for diagnosis, which makes it especially vulnerable to false positive diagnostic assignments (Langenbucher et al., 1996; Wakefield \& First, 2003). Persons with substance abuse problems often have completely nonoverlapping patterns of symptomatology, which are related to different outcomes (Hasin, Paykin, Endicott, \& Grant, 1999). We conclude that DSM-IV substance abuse does not meet a reasonable standard for being considered a mental disorder.

\section{The Criterion Sets for Substance Abuse and Dependence Do Not Differ in Prevalence or Severity}

The DSM-IV's abuse and dependence symptom categories do not differ in their prevalence in clinical and community samples (e.g., Chung, Martin, Armstrong, \& Labouvie, 2002). Instead, both categories include criteria that are more and less common. Thus, data are not consistent with the concept of relatively mild and severe illness categories that differ in the relative severity of their diagnostic criteria. Similar results have been obtained using the item response theory (IRT) measure of item threshold, which quantifies symptom severity along a latent trait of substanceproblem severity. Item threshold does not distinguish the abuse and dependence criterion sets for alcohol and other substances in clinical samples of adults (Langenbucher et al., 2004) and adolescents (Martin, Chung, Kirisci, \& Langenbucher, 2006) and in community samples of adults for alcohol (Kahler \& Strong, 2006; Krueger et al., 2004; Proudfoot, Baillie, \& Teesson, 2006) and other drugs (Lynskey \& Agrawal, 2007). Instead, the criterion sets for both disorders contain items that are more and less severe.

\section{Factor and Latent Class Analyses Indicate a Single Dimension of Substance Problems}

The mutually exclusive groups of abuse and dependence symptoms in the DSM-IV imply separate factors of substance problems. Factor structure results from a variety of samples indicate that the $D S M-I V$ SUD criteria are best modeled as a single dimension of substance problems rather than as separate $D S M-I V$ abuse and dependence factors (or other two- or higher-order factor solutions; e.g., Fulkerson, Harrison, \& Beebe, 1999; Krueger et al., 2004; Langenbucher et al., 2004; Lynskey \& Agrawal, 2007; Martin, Chung, et al., 2006; Muthen, 2006; Saha, Chou, \& Grant, 2006; Teesson, Lynskey, Manor, \& Baillie, 2002). Those who have reported factor structure solutions described as consistent with the $D S M-I V$ did not report comparisons of fit with a one-factor model and found that the distribution of criteria between factors did not follow the $D S M-I V$ in a number of cases (e.g., B. F. Grant, Harford, Muthen, Yi, Hasin, \& Stinson, 2007). Adolescent and adult studies using latent class analysis, a person-centered data analytic approach that identifies subgroups of individuals with similar symptom profiles, have consistently found classes that differ in the total number of symptoms rather than the type of symptoms (e.g., abuse vs. dependence classes) for alcohol (Bucholz, Heath, \& Madden, 2000; Bucholz et al., 1996; Chung \& Martin, 2001; Muthen, 2006), cannabis (J. D. Grant, Scherrer, Neuman, Todorov, Price, \& Bucholz, 2006), and cocaine and opiates (Chung \& Martin, 2005a), despite the fact that this analytic technique is well suited to detect discrete substance problem subtypes. When cross-classified, latent classes and DSM-IV diagnoses show a significant level of discordance (Chung \& Martin, 2001, 2005a).

\section{Substance Abuse and Dependence Symptoms and Disorders Are Not Distinguished by Age of Onset}

The DSM-IV's hierarchical decision rule that a diagnosis of dependence precludes abuse implies relatively mild and severe illness categories and diagnostic criteria that should differ in their age of onset. However, survival analyses have shown that alcohol abuse and dependence symptom groups are not distinguished by time to symptom onset in both adults and adolescents (Langenbucher \& Chung, 1995; Martin et al., 1996). Similarly, at the level of disorders, many persons first meet the criteria for dependence before they meet the criteria for abuse. Langenbucher et al. (2000) found that alcohol abuse preceded alcohol dependence in only $68.2 \%$ of clinical adolescents and $66.8 \%$ of clinical adults. A substantial number of those with SUDs in community samples 
have dependence without abuse (e.g., B. F. Grant, 1996; Hasin \& Grant, 2004), indicating the presence of at least three dependence symptoms in the absence of any abuse symptoms. These results clearly demonstrate that it is a mistake to use DSM-IV abuse symptoms as a screen for assessing dependence symptoms, as was done in a number of prominent studies, such as the National Comorbidity Study Replication and the World Mental Health Survey (B. F. Grant, Compton, et al., 2007; Kessler \& Merikangas, 2007).

\section{Predictive Validity Studies Have Not Shown Substance Abuse and Dependence to Be Separate Illness Categories}

Hasin, Van Rossem, McCloud, and Endicott (1997) found that community respondents with dependence were more likely to have an SUD at follow-up than were those with abuse. Alcohol abuse is particularly transient among adolescents and young adults (Nelson \& Wittchen, 1998). Other studies have shown that most adults in community samples with alcohol abuse do not transition to alcohol dependence (B. F. Grant, Stinson, \& Harford, 2001; Hasin \& Paykin, 1999). Schuckit et al. (2001) studied clinical adults in a 5-year follow-up and found that dependence predicted a more chronic course of alcohol problems than did abuse. Predicting distinct outcomes between those with different disorders is a key test of diagnostic validity (Robins \& Guze, 1970). However, simply showing differences in outcomes between DSM-IV SUD diagnostic groups is a weak test of predictive validity. This is because of the well-known fact that those with abuse and dependence tend to have substantial differences in substance-problem severity, including the total number of DSM-IV symptoms. To our knowledge, no study has shown that distinct dimensions or factors of substance problems (as defined in the DSM-IV or otherwise) predict clinical course above and beyond severity itself. This is an important area for future research, but it is quite possible that there are no specific symptom profiles that predict clinical course beyond the well-established phenomenon that substance-problem severity predicts worse outcomes.

\section{Diagnostic "Orphans" and "Impostors"}

Another problem indicated by data is that the $D S M-I V$ diagnostic algorithms for substance abuse (one of four criteria) and dependence (three of seven criteria) create unequal diagnostic coverage among those with similar levels of substance problems. Many adolescents and adults in clinical and community samples are "diagnostic orphans" with one or two dependence symptoms and no DSM-IV SUD (e.g., Chung et al., 2002; Degenhardt, Lynskey, Coffey, \& Patton, 2002; Hasin \& Paykin, 1998; Lynskey \& Agrawal, 2007). Orphans show levels of substance use and related problems over follow-ups that are similar to those with DSM-IV substance abuse (Eng, Schuckit, \& Smith, 2003; Hasin \& Paykin, 1998; Pollock \& Martin, 1999). On the other hand, because DSM-IV abuse has a one-symptom threshold for diagnosis, some adolescents with relatively low levels of alcohol use qualify for an alcohol abuse diagnosis merely due to significant problems with their parents and can be considered "diagnostic impostors" (Langenbucher et al., 1996).
Variability in the Ratio of DSM-IV Abuse to Dependence Diagnoses

$D S M-I V$ diagnostic algorithms have been shown to contribute to high levels of variation in the estimated rates of alcohol use disorders (AUDs). In a review of four adolescent community samples making lifetime diagnoses, Chung et al. (2002) found that the rates of alcohol abuse ranged from $0.4 \%$ to $9.6 \%$ (a 24-fold difference) and that rates of dependence ranged from $0.6 \%$ to $4.3 \%$ (a 7-fold difference). Although regional, sampling, and other differences between studies likely contributed to the observed variation in AUD rates, one would still expect that a valid diagnostic system would produce some stability in the ratio of abuse to dependence diagnoses across studies. However, this ratio ranged more than 11-fold, from 0.4 to 1 to 4.5 to 1 . Differences in how certain symptoms were assessed contributed to the variation in adolescent AUD rates observed by Chung et al. (2002) because $D S M-I V$ diagnostic algorithms are highly vulnerable to crossstudy differences in the prevalence of even one or two symptoms, which move many persons into or out of the abuse and dependence categories. It is disconcerting that apparently small differences in how some symptoms are assessed can have such a large downstream effect on estimated rates of DSM-IV AUDs.

Large variations in the ratio of abuse to dependence diagnoses have also been observed in adult clinical and community samples (B. F. Grant, 1992; Langenbucher et al., 1994). B. F. Grant et al. (2004) compared secular trends in the past-year national prevalence of DSM-IV AUDs using data from the National Longitudinal Alcohol Epidemiologic Survey (1991-1992) and the National Epidemiologic Survey on Alcohol and Related Conditions (20012002), which used very similar sampling techniques and the same diagnostic measure. Across this decade, the prevalence of abuse increased from $3.03 \%$ to $4.65 \%$, whereas the prevalence of dependence decreased from $4.38 \%$ to $3.81 \%$. Therefore, the ratio of abuse to dependence changed substantially over time from 0.69 to 1 to 1.22 to 1 . Although B. F. Grant et al. did not analyze data at the level of symptoms, these results suggest that secular trends in the prevalence of individual criteria may have had large effects on the prevalence of $D S M-I V$ disorders and their ratio.

\section{Proposed Definitions and Diagnostic Algorithms for SUDs in the DSM-V}

Taken together, these results clearly indicate that the $D S M-I V$ 's mutually exclusive abuse and dependence criteria are not tenable. Instead, the data are consistent with the idea that SUDs should be diagnosed using a single set of criteria, obtained at least in part by combining most of the DSM-IV abuse and dependence symptoms. Conceptual and empirical problems with the substance abuse diagnosis, and conceptual ambiguity surrounding the term abuse, are sufficient to warrant abandoning this category and this terminology in the $D S M-V$. This would produce a dichotomous classification scheme of disorder present or absent, as is common in psychiatry (American Psychiatric Association, 1993).

Although current diagnostic criteria are best modeled as reflecting a unidimensional continuum of substance-problem severity, this does not mean that there are not multiple addiction constructs, such as physical dependence, incentive salience, and impaired control. Instead, it appears that these features tend to onset and 
develop together, such that few persons have distinct patterns of some but not other of these features. Although it seems unlikely given extant data, it remains possible that distinct factors of substance problems could be found, for example in research that uses new or revised diagnostic criteria. Such evidence could then potentially provide the basis for separate SUD diagnoses. It is also important to develop and test new diagnostic models that try to distinguish between developmentally limited versus persistent forms of SUDs, although it is unclear that there exist distinct symptom profiles that could predict these outcomes above and beyond severity. Unless and until such evidence emerges, a unified criterion set should be used to diagnose a single SUD in the $D S M-V$.

More research is needed to examine the performance of such a model at different diagnostic thresholds. Because SUD symptom count shows a continuous and fairly linear association with other measures of substance involvement (e.g., Hasin, Schuckit, Martin, Grant, \& Helzer, 2003), it is highly unlikely that a diagnostic threshold will be determined by finding discontinuities in the association of symptom count with external validators or clinical course. This does not mean that the choice of diagnostic threshold is arbitrary. Instead, the threshold should be designed to avoid what can be considered false positive diagnostic assignments (Caetano \& Babor, 2006; Wakefield \& First, 2003) and to reflect professional judgments of the importance of treating substance problems at a certain level of severity and the personal and societal costs of not doing so (Krueger et al., 2004; Langenbucher, Martin, et al., 2000). Whatever the diagnostic threshold, we recommend that the $D S M-V$ continue to require clinically significant distress or impairment for an SUD diagnosis (Spitzer \& Wakefield, 1999).

There are several clear advantages to this type of diagnostic model. It reflects the underlying structure of SUD criteria, solves problems of unequal diagnostic coverage between diagnostic orphans and those with substance abuse, and ensures that symptom count is always associated with diagnostic status. As detailed below, this model is far superior to the $D S M-I V$ in providing a framework that integrates categorical and dimensional approaches to diagnosis. For example, although the $D S M-V$ will need to specify an official cutoff point for an SUD diagnosis, the manual also can describe multiple sub- and super-threshold cutoff points that can be used to guide clinical decisions, such as the appropriate level of care (Buhringer, 2007).

We believe that this single $D S M-V$ SUD should be called substance dependence. O'Brien, Volkow, and Li (2006) argued that the term dependence should be replaced by the term addiction in the $D S M-V$. Their rationale was that the term dependence can be used to refer to physiological adaptation to repeated uses of a medication without compulsive drug taking and that the inclusion of this term in various editions of the DSM has contributed to physicians undermedicating patients with chronic pain. However, the extent to which the change in terminology would affect prescribing practices is unclear, and it would come at the cost of changing a term that has been a basic feature of the diagnostic nomenclature for decades. Consistent with Erikson (2008) and Miller (2008), our view is that addiction is a more pejorative and scientifically vague term than dependence, although Hasin (2008) noted a lack of research on public and professional attitudes toward and understanding of the two terms.
Individual SUD Criteria in the DSM-IV and Suggested Revisions Leading to the $D S M-V$

\section{Distinguishing Diagnostic Criteria and the Methods Used to Assess Them}

This section describes proposed changes to some of the DSM$I V$ 's individual SUD criteria, including symptoms that should be revised, dropped, or considered for inclusion in the $D S M-V$. Individual criteria serve as the building blocks for diagnosis, but it is often difficult to define and assess symptoms in a way that optimizes measurement of the addiction constructs they were intended to reflect. In evaluating the validity of individual criteria, it is important to distinguish between the definitions of the criteria in the manual and the processes used to assess them, which are largely self-report. That is, a diagnostic criterion can be problematic either because its definition fails to adequately capture the nature of the clinical phenomenon or because accurate responses require persons to report more than they are able due to limitations in recall, self-awareness, or conceptual understanding of the phenomenon being queried (Babor, 2007). The validity shown by individual criteria can be affected by any of these potential problems. Although distinct, these problems are related to one other. A symptom that is not well-defined or is relatively complex is more likely to show problems in how well persons can provide accurate self-reports. This is particularly the case when symptom queries repeat the criterion definition verbatim, and interviewers are not used to ask follow-up questions, clarify the meaning of the symptom, or use clinical judgment in assigning symptoms.

Robins (1989) noted the importance of "diagnostic grammar" when developing operational definitions of diagnostic criteria. Importantly, the language used to operationalize symptoms can have a substantial impact in determining how frequently a symptom is observed (Babor, 2007; Kahler \& Strong, 2006). Potential criteria should be generated and evaluated in different clinical and community samples, taking into consideration age, gender, and culture, to minimize possible measurement error. DSM-IV SUD criteria were developed largely from clinical experience with adults, and when applied to more youthful and community samples, certain criteria can degrade diagnostic validity by producing apparent false positive and false negative cases of symptom assignment.

\section{Tolerance}

The $D S M-I V$ defines tolerance as a marked increase in consumption to obtain the same effect or a decreased effect at the same dose. In terms of diagnostic assessment, this change-based definition is problematic. The time frame over which such changes should be assessed is not specified and can range from days to years. Data show that alcohol and cannabis tolerance have relatively high prevalence in teens (Chung et al., 2002) and do little better than chance in discriminating between those with and without dependence (Chung, Martin, Winters, Cornelius, \& Langenbucher, 2004; Chung, Martin, Winters, \& Langenbucher, 2001). IRT analyses indicated that tolerance provided relatively poor discrimination of alcohol and cannabis problem severity in a clinical sample of adolescents (Martin, Chung, et al., 2006). Many adolescents with high levels of problem severity are not assigned 
tolerance because they report heavy use that began during initial and early use episodes and do not report subsequent marked increases in the amount used to produce the same effect. This may reflect recall biases, a rapid rate of tolerance development during early drug exposures, or innate differences in sensitivity to drug effects. Other adolescents and young adults who are assigned tolerance do report a marked increase to produce the same effect in the context of relatively low levels of use (e.g., an increase from two to three drinks; Caetano \& Babor, 2006; Chung et al., 2001, 2004).

To address these issues, the $D S M-I V$ definition of tolerance should be revised. The text revision of the DSM-IV (American Psychiatric Association, 2000, p. 218) describes one alternative: a person who shows no signs of intoxication at a specified blood alcohol concentration (BAC). This definition is limited to alcohol and by the ability to determine an individual's BAC and intoxication level. Nevertheless, one potential way to revise tolerance is to assign the symptom when substance use is sufficiently heavy to reasonably infer physiologic adaptation to its acute effects, even if a person does not endorse the change-based components of the symptom. Furthermore, tolerance should not be assigned to persons with relatively low levels of substance use. For alcohol, we recommend that in order to get tolerance, persons must consume enough alcohol to reach a BAC of $.08 \mathrm{~g} \%$ an average of at least once per month over the past year, corresponding to drinking $5+$ (average man) or 4+ (average woman) U.S. standard drinks within $2 \mathrm{hr}$, in addition to reporting a marked increase to produce the same effect or a decreased effect at the same dose. Such quantities cannot be specified for illicit drugs, but there could be a frequency of use cutoff point (e.g., once/month), and the manual could specify that clinical judgment is required to determine whether use levels are sufficiently high to warrant the assignment of this symptom. Revised definitions of tolerance should be tested in diverse samples for their ability to discriminate levels of substance-problem severity (Room, Janca, Bennett, Schmidt, \& Sartorius, 1996).

\section{Consumption Criterion}

We agree with Li, Hewitt, \& Grant (2007) and Saha, Stinson, \& Grant (2007) that relatively heavy alcohol consumption should be an AUD criterion in the $D S M-V$. Including such a criterion has important benefits, such as assessing milder levels of substance involvement and assigning a symptom to those heavy users who do not report tolerance. Saha et al. (2007) used IRT analyses of National Epidemiologic Survey on Alcohol and Related Conditions data to show that among adults, drinking 5+ (men) and 4+ (women) U.S. standard drinks showed good discrimination at the lower end of an alcohol-problem severity continuum and was invariant across race and age. These investigators studied three frequency cutoff points and found that once per week was preferable to once per month or once per year based on model fit and to ensure the clinical significance of the criterion. The $5+/ 4+$ criterion is consistent with epidemiological evidence of increased adverse consequences of drinking as the frequency of the $5+/ 4+$ pattern increases (e.g., Dawson, Grant, \& Li, 2005). However, as with the National Institute on Alcohol Abuse and Alcoholism's (2004, 2005) definition of binge drinking, the DSM-V should define an alcohol consumption criterion as a pattern of drinking that brings BACs to at least $.08 \mathrm{~g} \%$. This pattern of drinking should occur on average at least once per week over the course of a year. The manual should note that a BAC of $.08 \mathrm{~g} \%$ corresponds to drinking $5+/ 4+$ drinks for the average man and woman in about $2 \mathrm{hr}$ but will vary by weight, body composition, and the duration of drinking episodes. Although the $5+/ 4+$ guideline can be used for assessment in some applications, such as survey research or screening, the $.08 \mathrm{~g} \%$ BAC definition will allow more accurate diagnostic assessment in other cases. More research is needed to examine the utility of consumption criteria for drugs other than alcohol. Given that illicit drugs are not consumed in specific quantities and vary in concentration and purity, the consumption criterion should be defined by frequency, such as using on average once a week over the past year.

\section{Withdrawal as an Indicator of a Physiological Features Subtype of Dependence}

Withdrawal reflects neuroadaptation to the acute effects of substances and is defined in the $D S M-I V$ as "a maladaptive behavioral change, with physiological and cognitive concomitants, that occurs when blood or tissue concentrations of a substance decline in an individual who had maintained prolonged heavy use of the substance" (American Psychiatric Association, 1994, p. 178). Withdrawal is defined by drug-specific subalgorithms that specify the number of reported subcriteria that occur after the cessation of use (American Psychiatric Association, 2000). These subcriteria were developed from substantial clinical research on well-established phenomena, such as the alcohol withdrawal syndrome (e.g., Gross, Lewis, \& Hastey, 1974). Long considered a severe symptom, alcohol and other drug withdrawal (but not tolerance) has particular prognostic significance in predicting a worse course of alcohol and other drug problems (Hasin, Paykin, Meydan, \& Grant, 2000; Langenbucher, Martin, et al., 2000; Schuckit et al., 1998, 1999, 2003). These results support the utility of the $D S M-I V$ 's physiologic features subtype but also indicate that the $D S M-I V$ definition of a physiologic subtype-tolerance or withdrawal-should be changed in the $D S M-V$ to withdrawal only.

\section{Alcohol Withdrawal}

Despite its prognostic significance and severity in clinical samples, DSM-IV alcohol withdrawal has shown relatively high rates of endorsement and only moderate levels of problem severity when assessed in some community samples (e.g., Kahler \& Strong, 2006; Krueger et al., 2004; Saha et al., 2007). Our concern here is that the DSM-IV subalgorithm for alcohol withdrawal-which requires only two of eight subcriteria—can easily lead to false positive symptom assignments (Caetano \& Babor, 2006). Indeed, IRT (Kahler \& Strong, 2006) and receiver operating characteristic analyses (Langenbucher, Chung, et al., 2000) indicate that alcohol withdrawal subcriteria show a wide range of severity and that less severe items, such as anxiety and vomiting, may be particularly vulnerable to false positive reports. Hasin et al. (2000) found that the prognostic significance of withdrawal became greater when the subcriterion of tremors was required for symptom assignment, as was the case in the DSM-III-R. Because clinical research indicates that withdrawal is a severe symptom with prognostic significance, our view is that specificity must take precedence over sensitivity in 
choosing a subalgorithm. Therefore, the DSM-IV's subalgorithm for alcohol withdrawal should be revised to become more strict. Researchers should examine the effects of removing such subcriteria with poor specificity for withdrawal, increasing the cutoff point for symptom assignment, or making one or more subcriteria necessary for symptom assignment, on the association of the DSM symptom with independent measures of withdrawal and dependence severity.

\section{Cannabis Withdrawal}

Although withdrawal is not a criterion for cannabis dependence in the DSM-IV, considerable animal and human clinical research indicates that there is a coherent, measurable, and clinically significant cannabis withdrawal syndrome (Budney, 2006; Budney, Hughes, Moore, \& Vandrey, 2004). Martin, Chung, et al. (2006) found that, compared to alcohol, the DSM-IV cannabis criteria are especially poor at scaling more severe levels of cannabis problems and suggested that this might improve with the inclusion of a cannabis withdrawal criterion. Lynskey and Agrawal (2007) found that items measuring cannabis withdrawal correlated highly with other diagnostic criteria and comprised a relatively severe measure of cannabis problems. As with other drugs, more research is needed to determine the optimal subalgorithm for cannabis withdrawal. Chung, Martin, Cornelius, and Clark (in press) found that the 4 of 11 subcriteria definition proposed by Budney et al. (2004) predicted the severity of cannabis involvement at a 1-year follow-up in treated adolescents. Cottler and Grant (2006) listed data sets that are well-suited to exploring potential withdrawal syndromes for hallucinogens, phencyclidine, and inhalants.

\section{Larger/Longer}

The dependence symptom of "often using substances in larger amounts or for longer periods of time than intended" was designed to index impaired control over substance use (DSM-IV, p. 194). Schuckit et al. (2003) found that larger/longer was the only DSM-IV AUD symptom with no predictive validity among adults with alcohol dependence. Chung and Martin (2002) found that larger/longer showed relatively poor discrimination of substance-problem severity. Many clinical adolescents with heavy use patterns do not receive the larger/ longer symptom because they report that they do not set any limits on their substance use behavior. This criterion's high (yet highly variable) prevalence may be the result of misinterpretation of what the criterion is intended to assess (Caetano \& Babor, 2006; Chung \& Martin, 2005b; Chung et al., 2002). Some individuals with relatively low levels of use, when probed about their endorsement of this criterion, reported that they used more than intended due to social rather than compulsion-based reasons (Caetano \& Babor, 2006; Chung \& Martin, 2005b). We recommend that the $D S M-V$ better specify that this symptom should not be assigned if there is not evidence of a clinically significant pattern of compulsive use. Further, research is needed to clarify the definition of "often," that is, the proportion of use episodes in which a person uses more or longer than intended. In addition to revisions to the $D S M-V$ itself, survey and interview measures of larger/longer could try to reduce measurement error by breaking the criterion into simpler components, specifying limit-setting, and clarifying the importance of impaired control as the mechanism underlying difficulties in keeping to preset limits.
Our view that larger/longer is problematic is at odds with Saha et al. (2006), who argued that this symptom serves as an important "bridging criterion" that links the less severe end of an alcohol problems continuum with more severe symptoms. Several community-based IRT studies have shown that larger/longer showed good discrimination performance at relatively low levels of problem severity, indicating promising measurement characteristics (Kahler \& Strong, 2006; Proudfoot et al., 2006; Saha et al., 2006). Despite these results, it seems likely that the survey items used to assess larger/ longer led to many false positive symptom assignments (Caetano \& Babor, 2006), such that the questions did not adequately measure the intended meaning of the symptom. Responses to questions about larger/longer in these surveys may instead reflect something about relatively heavy patterns of drinking.

\section{Quit/Cut Down}

This symptom assesses a persistent desire, or repeated unsuccessful attempts, to quit or cut down on substance use. Studies that have separately assessed these symptom subdomains have found that a persistent desire to quit or cut down reflects lower levels of problem severity than actual unsuccessful attempts to quit or cut down do (Chung \& Martin, 2002; Kahler \& Strong, 2006; Lynskey \& Agrawal, 2007). These results suggest that splitting this symptom into two individual criteria may allow sharper diagnostic distinctions.

Martin, Chung, et al. (2006) found that, compared with many other symptoms, quit/cut down showed relatively poor discrimination of alcohol and cannabis problem severity in clinical adolescents. As with the larger/longer symptom, it should be noted that many of those with heavy use patterns are not assigned quit/cut down because they do not report attempts or a desire to limit use, whereas others with lower problem severity do report this symptom. Ironically, many persons fully meet the criteria for $D S M-I V$ dependence only after they wish or attempt to make the positive behavioral change of limiting their use, which then makes them eligible for certain dependence symptoms (Chung \& Martin, 2005b; Martin, Fillmore, Chung, Easdon, \& Miczek, 2006). These results indicate a need to develop and consider potential criteria that reflect unconstrained appetitive patterns of heavy use among those who report not trying to control their use, such as becoming very intoxicated during most episodes of use.

\section{Hazardous Use and Legal Problems}

Unlike all of the other $D S M-I V$ criteria, hazardous use and legal problems are defined in such a way that they do not reflect either compulsive patterns of use or physiologic features. The hazardous use symptom is unique in that it is defined only by risky behavior. Hazardous use typically is assigned due to intoxicated driving, and those without access to a car are unlikely to have this symptom. Hasin et al. (1999) found that among adults, drunk drivers were distinct from those with other patterns of alcohol abuse symptoms. Martin, Chung, et al. (2006) found that both of these criteria showed relatively poor discrimination of alcohol and cannabis problem severity in clinical samples of teens. Similar results have been reported in community samples of adults for alcohol (Kahler \& Strong, 2006; Proudfoot et al., 2006) and for eight other drug classes (Lynskey \& Agrawal, 2007). In two other studies, legal 
problems was not included in IRT analyses because it did not load adequately onto a unitary substance problem factor (Langenbucher et al., 2004; Saha et al., 2006). B. F. Grant, Harford, et al. (2007) found that legal problems did not load significantly onto any factor in two-, three- and four-factor models of AUD criteria. Hazardous use showed a lower prevalence and higher severity in community samples from Australia (Proudfoot et al., 2006) compared to in the United States (e.g., Krueger et al., 2004; Saha et al., 2007), perhaps reflecting differences in national policies toward drunk driving. Kahler and Strong (2006) found that the relative severity of lifetime reports of hazardous use decreased with increasing age, suggesting that secular trends related to the enforcement of drunk driving in the United States may have changed the level of problem severity indexed by this symptom.

In clinical teens, hazardous use and legal problems are predicted by male gender, severity of conduct problems, and older age (Martin, 1999), and these symptoms are associated with higher levels of problem severity in women compared to men (Martin, Chung, et al., 2006). Similar results were reported in adult community studies by Saha et al. (2006) for hazardous use and by Kahler and Strong (2006) for legal problems. These results likely reflect that these symptoms index antisociality, which is more common in men than it is in women. The lack of gender invariance introduces bias, as these criteria do not perform similarly in men and women.

Taken together, these results lead us to recommend that hazardous use and legal problems be removed as diagnostic criteria for SUDs in the $D S M-V$. There is no doubt that intoxicated driving is a major public health problem and that substance use and legal problems are often associated. Nevertheless, substance-related illegal behavior serves as a criterion for adolescent conduct disorder (CD) and adult antisocial personality disorder (ASPD). Hazardous use and substance-related legal consequences should be reflected in the $D S M-V$, not as SUD criteria, but in how the manual describes antisocial behaviors and disorders as well as an externalizing spectrum of psychopathology.

\section{Research Questions Regarding Other DSM-IV SUD Symptoms}

There are a number of other issues regarding individual $D S M-I V$ criteria that require additional study and should be considered in the $D S M-V$ development process. The high yet variable prevalence of the much time spent using symptom (Chung et al., 2002) suggests that better operational definitions for what constitutes "much time" would allow this criterion to be assessed more consistently. Research is needed to provide better guidelines for defining terms such as persistent and recurrent that are used to characterize many symptoms (Bailey, Martin, Lynch, \& Pollock, 2000; Spitzer \& Wakefield, 1999). Data are needed to examine the effects of splitting the physical/psychological problems criterion, which describes diverse subdomains. Substance-related psychological problems are relatively common in adolescents with substance problems (e.g., Martin, Kaczynski, Maisto, Bukstein, \& Moss, 1995), whereas physical problems tend to become evident only after years of heavy use (Vaillant, 1983).
Integrating Categorical and Dimensional Approaches to SUD Diagnoses in the $D S M-V$

\section{Overview}

It is clear that the $D S M-V$ needs to retain categorical diagnoses for SUDs and other disorders in order to guide treatment decisions, insurance coverage, and inclusion in research studies. At the same time, it is increasingly recognized that substantial information is lost when only a categorical approach is employed, and there is a great deal of interest in adding a dimensional component to the DSM-V (e.g., Helzer, Van Den Brink, \& Guth, 2006; Krueger, Watson, \& Barlow, 2005; Widiger \& Trull, 2007). Rather than having to reflect either a categorical or a dimensional approach, it is increasingly recognized that the $D S M-V$ should accommodate both perspectives (Kupfer et al., 2002). Many forms of psychopathology show both continuous and discontinuous associations with other phenomena or processes, so it is important to be able to use either a dimensional or categorical approach depending on the function diagnosis is intended to serve in a particular application (Pickles \& Angold, 2003).

The concept of dimensional approaches to diagnosis is multifactorial and can occur at the levels of individual symptoms and syndromes as well as at the superordinate structure of psychopathology. The $D S M-V$ should address each of these levels of dimensionality. These considerations are related to the concepts of spectrum nosology that have been largely developed in research on affective and anxiety disorders (Maser \& Patterson, 2002). Spectrum nosology emphasizes subthreshold manifestations of disorder, the importance of scaling severity among those who are above a diagnostic threshold, and noncriterion signs and symptoms associated with a disorder. Spectrum nosology is also concerned with how disorders that have traditionally been seen as separate forms of psychopathology may be associated with each other (Phillips, Price, Greenberg, \& Rasmussen, 2003; Widiger \& Clark, 2000). In this way, spectrum nosology provides a perspective on comorbidity that emphasizes shared underlying etiological risk factors for multiple disorders that share common features.

\section{Dimensional Approaches at the Criterion Level}

At the level of individual symptoms, the $D S M-I V$ often does not clarify the boundary at which a symptom should be considered present, for example by providing guidelines for what constitutes often or recurrent. Importantly, the Structured Clinical Interview for the DSM (First, Spitzer, Gibbon, \& Williams, 1997) provides a system for rating each symptom as absent, subclinical, or clinically present, allowing clinicians to not have to make dichotomous symptom ratings in ambiguous cases. Martin et al. (1995) adapted the SUD section of the Structured Clinical Interview for the DSM for adolescents and included specific guidelines for rating many symptoms as clinically present. Bailey et al. (2000) used data from this interview to establish that those with absent, subclinical, and clinically present symptom ratings tended to differ from each other in external measures of substance involvement, indicating the validity of this tripartite symptom rating system for SUD criteria among teens. Subclinical symptom ratings were most common in those with no diagnosis and least common in those with dependence, indicating that subclinical manifestations of SUD symp- 
toms may be an important early indicator of illness progression. Therefore, it would be helpful for the $D S M-V$ to better describe thresholds for the assignment of individual criteria and to provide examples of subclinical and clinical manifestations for certain symptoms. The manual should emphasize the importance of subclinical symptoms for early identification of those at risk for future impairment or disorder.

\section{Dimensional Approaches at the Syndrome Level}

The DSM-IV has problematic characteristics for incorporating dimensional approaches to diagnosis at the level of syndromes. The abuse criteria are not milder than the dependence criteria. Diagnostic status is not always associated with symptom count. For example, diagnostic orphans have up to two symptoms but no diagnosis, whereas many persons with substance abuse have only one symptom. Our suggested revisions to diagnostic criteria in the $D S M-V$ would effectively address these issues. Having a single disorder of substance dependence obviates concerns about the relative severity of abuse and dependence items. If a combined criterion set is used to diagnose substance dependence, symptom count would always be associated with diagnosis.

A dimensional approach to diagnosis emphasizes the importance of scaling severity among those who are above and below the threshold for a disorder (Helzer et al., 2006), as well as refining or adding symptoms to better measure a range of substance-problem severity. In this regard, numerous IRT studies in clinical and community samples of adults and adolescents have shown that DSM-IV criteria oversample pathology in the moderate range of severity and are especially less accurate in scaling relatively mild manifestations of substance problems (e.g., Kahler \& Strong, 2006; Krueger et al., 2004; Langenbucher et al., 2004; Martin, Chung, et al., 2006; Proudfoot et al., 2006; Saha et al., 2006, 2007). It could be argued that if a single diagnostic threshold at a particular level of severity was paramount, then it would be preferable for criteria to cluster around that level of severity (Muthen, 1996). However, this approach comes at great cost, including a limited ability to test alternative thresholds and to discriminate problem severity among sub- and super-threshold cases (Maser \& Patterson, 2002). We believe that an ideal set of criteria would be comprised of highly discriminating items that are distributed across a range of mild (but still clinically relevant) to severe levels of problem severity (Krueger et al., 2004). Therefore, research is needed to examine the potential inclusion of new criteria that may index relatively mild and severe substance problems. Some extant data sets include noncriterion features that can be studied in conjunction with current diagnostic criteria (Cottler \& Grant, 2006) to determine whether their inclusion would improve the measurement of a range of substance-problem severity (Li et al., 2007; Martin et al., 1995). Candidates include a consumption criterion (Saha et al., 2007), as well as any clinical problems known to be associated with dependence, such as the alcohol dependence syndrome and $I C D-10$ criteria of craving and rapid reinstatement of dependence after a return to use (Edwards \& Gross, 1976).

\section{Using a Variety of Symptom Cutoff Points for Different Clinical and Research Purposes}

If the $D S M-V$ uses a single criterion array that adequately scales severity, many clinical and research decisions can be made at levels other than at the threshold that defines the presence of a substance dependence diagnosis. Mild criteria can be used as screening items to determine the need for further assessment. With regard to subdiagnostic manifestations of substance problems, the $D S M-V$ should emphasize data on reduced functioning and risk for future disorder that occur among those with symptoms who do not meet full criteria for an SUD diagnosis (Pollock \& Martin, 1999). Beyond diagnosis, level of severity can be used to make clinical decisions about the appropriate level of care (Buhringer, 2007; Widiger \& Samuel, 2005). For example, the $D S M-V$ could describe symptom count ranges that correspond to mild, moderate, and severe substance dependence. In some research applications, a symptom cutoff that is higher than the diagnostic threshold can be used as an inclusion criterion to ensure "caseness." In many other cases, researchers should include those below and above the diagnostic threshold to better study severity as a continuous variable.

\section{Describing Noncriterion Features of Substance Problems in the DSM-V}

In addition to criterion symptoms used for diagnosis, the $D S M-V$ text should describe noncriterion risk factors, signs, symptoms, and correlates of substance problems (Li et al., 2007; Maser \& Patterson, 2002). This will allow clinicians and researchers to better incorporate associated features of SUDs in their work. It is important for the $D S M-V$ to distinguish between noncriterion features that are well established as part of a dependence process (e.g., craving, rapid reinstatement), are associated with other disorders (e.g., substance-related illegal behavior), involve unresolved or masked processes (e.g., unconstrained appetitive behavior among heavy users who do not try to control or limit use), or have the status of correlates with an uncertain theoretical relevance to a dependence syndrome (e.g., blackouts; Martin et al., 1995).

Further, the $D S M-V$ should describe substance-related consequences that are not considered disorders or criterion symptoms but deserve clinical consultation (e.g., with substance-related V codes). The manual should categorize the health, social, interpersonal, psychological, occupational, and legal consequences that often accompany substance use and SUDs (Li et al., 2007), indicating how these consequences vary by age, gender, and culture Finally, the manual should describe the current state of knowledge regarding biological and laboratory measures that may be used in the future to aid, confirm, or supplement self-reported diagnostic information (Hyman, 2007). Although no measure currently meets the standard of a biological marker for SUDs (Koob, 2006), the potential exists to develop measures with sufficient sensitivity and specificity that they could be used as part of a polythetic criterion set (First \& Zimmerman, 2006). Overall, a more comprehensive categorization and discussion of various noncriterion features in the $D S M-V$ will encourage researchers to incorporate them into future measurement protocols with clinical and community samples, providing data that will be useful for refining the criterion array in the sixth edition of the DSM (Helzer et al., 2006).

\section{SUDs and the Structure of Psychopathology in the DSM-V}

Spectrum nosology highlights the importance of the factor structure of psychopathology, that is, how traditionally separate types of disorder are hierarchically arranged and associated with each 
other. This is an area of potential revision for the $D S M-V$ that goes beyond the SUD task force, relating to how disorders are organized in the new manual. The DSM-IV groups disorders with regard to "shared phenomenological features," (American Psychiatric Association, 2000, p. 10) but this subjective approach can now be replaced with empirically based knowledge of the superordinate structure of disorders (Watson, 2005), as well as emerging knowledge regarding common etiological risk factors (Phillips et al., 2003).

In this regard, there is substantial evidence for an externalizing spectrum of psychopathology that incorporates different SUDs, adolescent CD, and adult antisocial behavior. Substance problems and antisocial behavior are well known to have a high rate of co-occurrence. Numerous studies of phenotypic structure have found that alcohol and drug problems and antisocial behavior form a coherent externalizing factor that is distinct from a separate factor formed by internalizing disorders (e.g., Kendler, Karkowski, Prescott, \& Pederson, 1997; Krueger, 1999; Krueger, Caspi, Moffitt, \& Wilva, 1998; Krueger, McGue, \& Iacono, 2001). Further, there is considerable evidence that there are shared underlying etiologic risk factors for the broad externalizing spectrum, although there are likely risk factors that are specific to the general category of SUDs and those that are specific to particular drugs (Krueger, Markon, Patrick, \& Iacono, 2005). Numerous twin studies have shown that there is a great deal of shared genetic risk between substance problems and antisocial traits and disorders (e.g., Fu et al., 2002; Krueger et al., 2002; Malone, Taylor, Marmorstein, McGue, \& Iacono, 2004; Mustanski, Viken, Kaprio, \& Rose, 2003; Pickens, Svikis, McGue, \& LaBuda, 1995). Kendler, Prescott, Myers, and Neale (2003) reported that genetic influences on an externalizing factor were distinct from those influencing an internalizing factor. In their work on a dimensionalspectrum model of externalizing psychopathology, Krueger, Markon, et al. (2005) found that comorbidity among externalizing syndromes was best modeled as an externalizing continuum of risk for multiple forms of pathology rather than discrete latent classes.

Given this evidence, we agree with Krueger, Markon, et al. (2005) that externalizing syndromes should be merged into a group of disorders in the $D S M-V$. This would mean moving CD from the heterogeneous group of Disorders Usually First Diagnosed in Infancy, Childhood and Adolescence (American Psychiatric Association, 2000), and perhaps more radically, moving ASPD out of Axis II and into Axis I. Although it is beyond the scope of this article, there is considerable discussion of problems with the distinction between Axis I and Axis II in the DSM-IV (e.g., Krueger \& Tackett, 2003), an area that may see major revision in the $D S M-V$ (Widiger \& Trull, 2007). In any case, the strong evidence for a coherent externalizing spectrum is not consistent with placing SUDs and ASPD (as well as CD and ASPD) on different axes.

Grouping externalizing disorders together in the $D S M-V$ would be useful for research and clinical practice. At a basic level, it will highlight for researchers, clinicians, and policy makers the associations among and risk factors underlying various externalizing behaviors, and the text accompanying this section of the $D S M-V$ should describe these issues and their implications for clinical practice. This could encourage clinical efforts to treat and prevent externalizing disorders more broadly and will highlight the importance of assessing a variety of externalizing pathology among those who present with problems from one part of the spectrum. Further, grouping externalizing syndromes together can help provide new perspectives on comorbidity (Clark, 2005; Widiger \& Samuel, 2005), which is the norm rather than the exception for those with substance and antisocial disorders. A traditional perspective suggests the presence of distinct clinical entities among comorbid individuals. A dimensional framework indicates how, in many cases, multiple disorders may reflect shared underlying pathologies. Hopefully this framework will encourage researchers to develop and test integrated hierarchical models of etiology that involve both spectrum-general and disorder-specific genetic and environmental risk factors.

\section{Conclusions}

Although our knowledge of the nature and structure of SUDs has advanced considerably since the publication of the DSM-IV, many nosologic issues remain controversial. This is due in part to the fact that substance-problem syndromes are complex and polythetic, involving multiple addiction constructs. Even compulsive use, which is consensually accepted as a core feature of substance dependence, is a highly complex construct with multiple neural and psychological subdomains and highly variable clinical manifestations (S. Grant, 2004; Martin, Fillmore, et al., 2006). Therefore, we expect that others will disagree with some of our recommendations for revisions to the SUD diagnostic criteria and express other viewpoints. We hope that our ideas, together with those of other investigators, will lead to increased discussion and further research, so that the $D S M-V$ can better serve patients, clinicians, researchers, policy makers, and the general public.

\section{References}

American Psychiatric Association. (1980). Diagnostic and Statistical Manual of Mental Disorders (3rd ed.). Washington, DC: Author.

American Psychiatric Association. (1987). Diagnostic and Statistical Manual of Mental Disorders (3rd ed., text revision). Washington, DC: Author.

American Psychiatric Association. (1993). DSM-IV Options Book. Washington, DC: Author.

American Psychiatric Association. (1994). Diagnostic and Statistical Manual of Mental Disorders (4th ed.). Washington, DC: Author.

American Psychiatric Association. (2000). Diagnostic and Statistical Manual of Mental Disorders (4th ed., text revision). Washington, DC: Author.

Babor, T. F. (2007). We shape our tools, and thereafter our tools shape us: Psychiatry epidemiology and the alcohol dependence syndrome concept. Addiction, 102, 1534-1535.

Bailey, S. L., Martin, C. S., Lynch, K. G., \& Pollock, N. K. (2000). Reliability and concurrent validity of DSM-IV sub-clinical symptom ratings for alcohol use disorders among adolescents. Alcoholism: Clinical and Experimental Research, 24, 1795-1802.

Bucholz, K. K., Heath, A. C., \& Madden, P. A. (2000). Transitions in drinking in adolescent females: Evidence from the Missouri adolescent female twin study. Alcoholism: Clinical and Experimental Research, 24, 914-923.

Bucholz, K. K., Heath, A. C., Reich, T., Hesselbrock, V. M., Kramer, J. R., Nurnberger, J. I., et al. (1996). Can we subtype alcoholism? A latent class analysis of data from relatives of alcoholics in a multicenter family study of alcoholism. Alcoholism: Clinical and Experimental Research, $20,1462-1471$.

Budney, A. J. (2006). Are specific dependence criteria necessary for 
different substances: How can research on cannabis inform this issue? Addiction, 101, 125-133.

Budney, A. J., Hughes, J. R., Moore, B. A., \& Vandrey, M. A. (2004). Review of the validity and significance of cannabis withdrawal syndrome. American Journal of Psychiatry, 161, 1967-1977.

Buhringer, G. (2007). The alcohol dependence syndrome: Consequences for DSM revisions. Addiction, 102, 1532-1533.

Caetano, R., \& Babor, T. F. (2006). Diagnosis of alcohol dependence in epidemiological surveys: An epidemic of youthful alcohol dependence or a case of measurement error? Addiction, 101, 111-114.

Chung, T., \& Martin, C. S. (2001). Classification and course of alcohol problems among adolescents in addictions treatment programs. Alcoholism: Clinical and Experimental Research, 25, 1734-1742.

Chung, T., \& Martin, C. S. (2002). Concurrent and discriminant validity of DSM-IV symptoms of impaired control over alcohol consumption in adolescents. Alcoholism: Clinical and Experimental Research, 26, 485492.

Chung, T., \& Martin, C. S. (2005a). Classification and short-term course of DSM-IV cannabis, hallucinogen, cocaine, and opioid disorders in clinical adolescents. Journal of Consulting and Clinical Psychology, 73, 995-1004.

Chung, T., \& Martin, C. S. (2005b). What were they thinking? Adolescents' interpretations of DSM-IV alcohol dependence symptom queries and implications for diagnostic validity. Drug and Alcohol Dependence, 80, 191-200.

Chung, T., Martin, C. S., Armstrong, T., \& Labouvie, E. (2002). Prevalence of DSM-IV alcohol diagnoses and symptoms in adolescent community and clinical samples. Journal of the American Academy of Child and Adolescent Psychiatry, 41, 546-554.

Chung, T., Martin, C. S., Cornelius, J. R., \& Clark, D. B. (in press). Cannabis withdrawal predicts severity of cannabis involvement at 1-year follow-up among treated adolescents. Addiction.

Chung, T., Martin, C. S., Winters, K. C., Cornelius, J. R., \& Langenbucher, J. W. (2004). Limitations in the assessment of DSM-IV cannabis tolerance as an indicator of dependence in adolescents. Experimental and Clinical Psychopharmacology, 12, 136-146.

Chung, T., Martin, C. S., Winters, K. C., \& Langenbucher, J. W. (2001). Assessment of alcohol tolerance in adolescents. Journal of Studies on Alcohol, 62, 687-695.

Clark, L. (2005). Temperament as a unifying basis for personality and psychopathology. Journal of Abnormal Psychology, 114, 505-521.

Cottler, L. B., \& Grant, B. F. (2006). Characteristics of nosologically informative data sets that address key diagnostic issues facing the Diagnostic and Statistical Manual of Mental Disorders, fifth edition (DSM-V) and the International Classification of Diseases, eleventh edition (ICD-11) substance use disorders workgroups. Addiction, 101, 161-169.

Dawson, D. A., Grant, B. F., \& Li, T. K. (2005). Quantifying the risks associated with exceeding recommended drinking limits. Alcoholism: Clinical and Experimental Research, 29, 902-908.

Degenhardt, L., Lynskey, M. T., Coffey, C., \& Patton, G. (2002). Diagnostic orphans among young adult cannabis users: Persons who report dependence symptoms but do not meet diagnostic criteria. Drug and Alcohol Dependence, 67, 205-212.

Edwards, G., \& Gross, M. M. (1976). Alcohol dependence: Provisional description of a clinical syndrome. British Medical Journal, 1, 10581061.

Eng, M. Y., Schuckit, M. A., \& Smith, T. L. (2003). A five-year prospective study of diagnostic orphans for alcohol use disorders. Journal of Studies on Alcohol, 64, 227-234.

Erikson, C. K. (2008). In defense of "dependence". Alcoholism: Clinical and Experimental Research, 32, 1-3.

Feighner, J. P., Robins, E., Guze, S. B., Woodruff, R. A., Winokur, G., \&
Munoz, R. (1972). Diagnostic criteria for use in psychiatric research. Archives of General Psychiatry, 26, 57-63.

First, M. B., Spitzer, R. L., Gibbon, M., \& Williams, J. B. W. (1997). Structured Clinical Interview for DSM-IV Axis I Disorders, Research Version, Non-patient edition (SCID-I/NP). New York: Biometrics Research, New York State Psychiatric Institute.

First, M. B., \& Zimmerman, M. (2006). Including laboratory tests in DSM-V diagnostic criteria. American Journal of Psychiatry, 163, 20412042.

Fu, Q., Heath, A. C., Bucholz, K. K., Nelson, E., Goldberg, J., \& Lyons, M. J. (2002). Shared genetic risk of major depression, alcohol dependence, and marijuana dependence: Contribution of antisocial personality disorder in men. Archives of General Psychiatry, 59, 1125-1132.

Fulkerson, J. A., Harrison, P. A., \& Beebe, T. J. (1999). DSM-IV substance abuse and dependence: Are there really two dimensions of substance use disorders in adolescents? Addiction, 94, 495-506.

Grant, B. F. (1992). Prevalence of the proposed DSM-IV alcohol use disorders: United States, 1988. British Journal of Addiction, 87, 309316.

Grant, B. F. (1996). DSM-IV, DSM-III, and ICD-10 alcohol and drug abuse/harmful use and dependence, United States, 1992: A nosological comparison. Alcoholism: Clinical and Experimental Research, 20, $1481-1488$.

Grant, B. F., Compton, W. M., Crowley, T. J., Hasin, D. S., Helzer, J. E., Li, T.-K., et al. (2007). Errors in assessing DSM-IV substance use disorders. Archives of General Psychiatry, 64, 379-380.

Grant, B. F., Dawson, D. A., Stinson, F. S., Chou, S. P., Dufour, M. C., \& Pickering, R. P. (2004). The 12-month prevalence and trends in DSM-IV alcohol abuse and dependence: United States, 1991-1992 and 20012002. Drug and Alcohol Dependence, 74, 223-234.

Grant, B. F., Harford, T. C., Muthen, B. O., Yi, H., Hasin, D. S., \& Stinson, F. S. (2007). DSM-IV alcohol dependence and abuse: Further evidence of validity in the general population. Drug and Alcohol Dependence, 86, $154-166$.

Grant, B. F., Stinson, F. S., \& Harford, T. (2001). The 5-year course of alcohol abuse among young adults. Journal of Substance Abuse, 13, $229-238$

Grant, J. D., Scherrer, J. F., Neuman, R. J., Todorov, A. A., Price, R. K., \& Bucholz, K. K. (2006). A comparison of the latent class structure of cannabis problems among adult men and women who have used cannabis repeatedly. Addiction, 101, 1133-1142.

Grant, S. (2004). Let's not be impulsive: Comments on Lubman et al. (2004). Addiction, 99, 1504-1505.

Gross, M. M., Lewis, E., \& Hastey, J. (1974). Acute alcohol withdrawal syndrome. In B. Kissin \& H. Begleiter (Eds.), The biology of alcoholism (pp. 191-263). New York: Plenum.

Hasin, D. S. (2008). Commentary on Erikson and Wilcox (2006): In defense of gathering evidence on changing "dependence" to "addiction" in DSM-V. Alcoholism: Clinical and Experimental Research, 32, 6-7.

Hasin, D. S., \& Grant, B. F. (2004). The co-occurrence of DSM-IV alcohol abuse in DSM-IV alcohol dependence: NESARC results on heterogeneity that differs by population subgroup. Archives of General Psychiatry, 61, 891-896.

Hasin, D., Hatzenbuehler, M. L., Keyes, K., \& Ogburn, E. (2006). Substance use disorders: Diagnostic and Statistical Manual of Mental Disorders, fourth edition (DSM-IV) and International Classification of Diseases, tenth edition (ICD-10). Addiction, 101, 59-75.

Hasin, D., \& Paykin, A. (1998). Dependence symptoms but no diagnosis: Diagnostic "orphans" in a community sample. Drug and Alcohol Dependence, $50,10-26$.

Hasin, D., \& Paykin, A. (1999). DSM-IV alcohol abuse: Investigation in a sample of at-risk drinkers in the community. Journal of Studies on Alcohol, 60, 181-187.

Hasin, D. S., Paykin, A., Endicott, J., \& Grant, B. (1999). The validity of 
DSM-IV alcohol abuse: Drunk drivers versus all others. Journal of Studies on Alcohol, 60, 746-755.

Hasin, D., Paykin, A., Meydan, J., \& Grant, B. (2000). Withdrawal and tolerance: Prognostic significance in DSM-IV alcohol dependence. Journal of Studies on Alcohol, 61, 431-438.

Hasin, D., Schuckit, M., Martin, C., Grant, B., \& Helzer, J. (2003). Validity of alcohol dependence: What do we know, what do we need to know? Alcoholism: Clinical and Experimental Research, 27, 244-252.

Hasin, D. S., Van Rossem, R., McCloud, S., \& Endicott, J. (1997). Differentiating DSM-IV alcohol dependence and abuse by course: Community heavy drinkers. Journal of Substance Abuse, 9, 127-135.

Helzer, J. E. (1994). Psychoactive substance abuse and its relation to dependence. In T. A. Widiger, A. J. Frances, H. A. Pincus, M. B. First, R. Ross, \& W. Davis (Eds.), DSM-IV sourcebook (Vol. 1, pp. 21-32). Washington, DC: American Psychiatric Association.

Helzer, J. E., Van Den Brink, W., \& Guth, S. E. (2006). Should there be both categorical and dimensional criteria for substance use disorders in DSM-V? Addiction, 101, 17-22

Hughes, J. R. (2006). Should criteria for drug dependence differ across drugs? Addiction, 101, 134-141.

Hughes, J. R. (2007). Defining dependence: Describing symptom clusters versus central constructs. Addiction, 102, 1531-1532.

Hyman, S. E. (2007). Can neuroscience be integrated into the DSM-V? Nature Reviews Neuroscience, 8, 725-732.

Jellinek, E. M. (1943). The alcohol problem: Formulations and attitudes. Quarterly Journal of Studies on Alcohol, 4, 446-461.

Jellinek, E. M. (1952). Phases of alcohol addiction. Quarterly Journal of Studies on Alcohol, 13, 673-684.

Kahler, C. W., \& Strong, D. R. (2006). A Rasch model analysis of DSM-IV alcohol abuse and dependence items in the National Epidemiological Survey on Alcohol and Related Conditions. Alcoholism: Clinical and Experimental Research, 30, 1165-1175.

Kendall, R. (1975). The role of diagnosis in psychiatry. Oxford, England: Blackwell Scientific Publications.

Kendler, K. S., Karkowski, L. M., Prescott, C. A., \& Pederson, N. L. (1997). The familial aggregation of common psychiatric and substance use disorders in the National Comorbidity Survey: A family history study. British Journal of Psychiatry, 170, 541-548.

Kendler, K. S., Prescott, C. A., Myers, J., \& Neale, M. D. (2003). The structure of genetic and environmental risk factors for common psychiatric and substance use disorders in men and women. Archives of General Psychiatry, 56, 929-937.

Kessler, R. C., \& Merikangas, K. R. (2007). Errors in assessing DSM-IV substance use disorders: In reply. Archives of General Psychiatry, 64, 381-382.

Koob, G. F. (2006). The neurobiology of addiction: A neuroadaptational view relevant for diagnosis. Addiction, 101, 23-30.

Koob, G. F., \& Le Moal, M. (1997). Drug abuse: Hedonic homeostatic dysfunction. Science, 278, 52-58.

Krueger, R. F. (1999). The structure of common mental disorders. Archives of General Psychiatry, 56, 921-926.

Krueger, R. F., Caspi, A., Moffitt, T. E., \& Wilva, P. A. (1998). The structure and stability of common mental disorders (DSM-III-R): A longitudinal-epidemiological study. Journal of Abnormal Psychology, 107, 216-227.

Krueger, R. F., Hicks, B. M., Patrick, C. J., Carlson, S. R., Iacono, W. G., \& McGue, M. (2002). Etiologic connections among substance dependence, antisocial behavior, and personality: Modeling the externalizing spectrum. Journal of Abnormal Psychology, 111, 411-424.

Krueger, R. F., Markon, K. E., Patrick, C. J., \& Iacono, W. G. (2005). Externalizing psychopathology in adulthood: A dimensional-spectrum conceptualization and its implications for DSM-V. Journal of Abnormal Psychology, 114, 537-550.
Krueger, R. F., McGue, M., \& Iacono, W. G. (2001). The higher-order structure of common DSM mental disorders: Internalization, externalization, and their connections to personality. Personality and Individual Differences, 30, 1245-1259.

Krueger, R. F., Nichol, P. E., Hicks, B. M., Markon, K. E., Patrick, C. J., Iacono, W. G., et al. (2004). Using latent trait modeling to conceptualize an alcohol problems continuum. Psychological Assessment, 16, 107119 .

Krueger, R. F., \& Tackett, J. L. (2003). Personality and psychopathology: Working toward the bigger picture. Journal of Personality Disorders, 17, $109-128$

Krueger, R. F., Watson, D., \& Barlow, D. H. (2005). Introduction to the special section: Toward a dimensionally based taxonomy of psychopathology. Journal of Abnormal Psychology, 114, 491-493.

Kupfer, D. J., First, M. B., \& Regier, D. A. (Eds.). (2002). A research agenda for DSM-V. Washington, DC: American Psychiatric Association.

Langenbucher, J., \& Chung, T. (1995). Onset and staging of DSM-IV alcohol dependence using mean age and survival-hazard methods. Journal of Abnormal Psychology, 104, 346-354.

Langenbucher, J., Chung, T., Martin, C., Labouvie, E., Bavley, L., \& Sanjuan, P. (2000, June). Item and algorithm analysis of DSM-IV subcriteria for alcohol withdrawal. Paper presented at the meeting of the College on Problems of Drug Dependence, San Juan, Puerto Rico.

Langenbucher, J. W., Labouvie, E., Martin, C. S., Sanjuan, P. M., Bavly, L., Kirisci, L., et al. (2004). An application of item response theory analysis to alcohol, cannabis, and cocaine criteria in DSM-IV. Journal of Abnormal Psychology, 113, 72-80.

Langenbucher, J. W., Martin, C. S., Hasin, D. S., \& Helzer, J. E. (1996). Alcohol abuse: Adding content to category. Alcoholism: Clinical and Experimental Research, 20, 270A-275A.

Langenbucher, J. W., Martin, C. S., Labouvie, E., Sanjuan, P. M., Bavly, L., \& Pollock, N. K. (2000). Toward the DSM-V: The withdrawal-gate model versus the DSM-IV in the diagnosis of alcohol abuse and dependence. Journal of Consulting and Clinical Psychology, 68, 799-809.

Langenbucher, J. W., Morgenstern, J., Labouvie, E., \& Nathan, P. E. (1994). Diagnostic concordance of substance use disorders in DSM-III, DSM-IV, and ICD-10. Drug and Alcohol Dependence, 36, 193-203.

Li, T.-K., Hewitt, B. G., \& Grant, B. F. (2007). The alcohol dependence syndrome, 30 years later: A commentary. Addiction, 102, 1522-1530.

Lynskey, M. T., \& Agrawal, A. (2007). Psychometric properties of DSM assessments of illicit drug abuse and dependence: Results from the National Epidemiologic Survey on Alcohol and Related Conditions (NESARC). Psychological Medicine, 37, 1345-1355.

Malone, S. M., Taylor, J., Marmorstein, N. R., McGue, M., \& Iacono, W. G. (2004). Genetic and environmental influences on antisocial behavior and alcohol dependence from adolescence to early adulthood. Development and Psychopathology, 16, 943-966.

Martin, C. S. (1999, June). Contrasting alternative diagnostic criteria for adolescent alcohol use disorders. In C. S. Martin (Chair), Diagnostic criteria for adolescent alcohol use disorders. Symposium conducted at the annual meeting of the Research Society on Alcoholism, Santa Barbara, CA.

Martin, C., Chung, T., Kirisci, L., \& Langenbucher, J. (2006). An item response theory analysis of diagnostic criteria for alcohol and cannabis use disorders in adolescents: Implications for DSM-V. Journal of Abnormal Psychology, 115, 807-814.

Martin, C. S., Fillmore, M. T., Chung, T., Easdon, C. M., \& Miczek, K. A. (2006). Multidisciplinary perspectives on impaired control over substance use. Alcoholism: Clinical and Experimental Research, 30, 265271.

Martin, C. S., Kaczynski, N., Maisto, S., Bukstein, O., \& Moss, H. (1995). 
Patterns of DSM-IV alcohol abuse and dependence symptoms in adolescent drinkers. Journal of Studies on Alcohol, 56, 672-680.

Martin, C. S., Langenbucher, J. W., Kaczynski, N., \& Chung, T. (1996). Staging in the onset of DSM-IV alcohol abuse and dependence symptoms in adolescents: Survival/hazard analyses. Journal of Studies on Alcohol, 57, 549-558.

Maser, J. D., \& Patterson, T. P. (2002). Spectrum and nosology: Implications for DSM-V. Psychiatric Clinics of North America, 25, 855-885.

Mikulich, S. K., Hall, S. K., Whitmore, E. A., \& Crowley, T. J. (2001). Concordance between DSM-III-R and DSM-IV diagnoses of substance use disorders in adolescents. Drug and Alcohol Dependence, 61, 237248

Miller, W. M. (2008). Dependence: Fear not. Alcoholism: Clinical and Experimental Research, 32, 4.

Millon, T. (1991). Classification in psychopathology: Rationale, alternatives, and standards. Journal of Abnormal Psychology, 100, 245-261.

Mustanski, B. S., Viken, R. J., Kaprio, J., \& Rose, R. J. (2003). Genetic influences on the association between personality risk factors and alcohol use and abuse. Journal of Abnormal Psychology, 112, 282289.

Muthen, B. (1996). Psychometric evaluation of diagnostic criteria: Application to a two-dimensional model of alcohol abuse and dependence. Drug and Alcohol Dependence, 41, 101-112.

Muthen, B. (2006). Should substance use disorders be considered as categorical or dimensional? Addiction, 101, 6-16.

National Institute on Alcohol Abuse and Alcoholism. (2004). Task force report on binge drinking. Rockville, MD: Author.

National Institute on Alcohol Abuse and Alcoholism. (2005). Helping patients who drink too much: A clinician's guide. Rockville, MD: Author.

Nelson, C., \& Wittchen, H.-U. (1998). DSM-IV alcohol disorders in a general population sample of adolescents and young adults. Addiction, 93, 1065-1077.

O'Brien, C. P., Volkow, N., \& Li, T.-K. (2006). What's in a word? Addiction versus dependence in DSM-V. American Journal of Psychiatry, 163, 764-765.

Petry, N. M. (2006). Should the scope of addictive behaviors be broadened to include pathological gambling? Addiction, 101, 152-160.

Phillips, K. A., Price, L. H., Greenberg, B. D., \& Rasmussen, S. A. (2003). Should the DSM diagnostic groupings be changed? In K. A. Phillips, M. B. First, \& H. A. Pincus (Eds.), Advancing DSM: Dilemmas in psychiatric diagnosis (pp. 57-84). Washington, DC: American Psychiatric Association.

Pickens, R. W., Svikis, D. S., McGue, M., \& LaBuda, M. C. (1995). Common genetic mechanisms in alcohol, drug and other mental disorder comorbidity. Drug and Alcohol Dependence, 39, 129-138.

Pickles, A., \& Angold, A. (2003). Natural categories or fundamental dimensions: On carving nature at the joints and the rearticulation of psychopathology. Development and Psychopathology, 15, 529-551.

Pollock, N. K., \& Martin, C. S. (1999). Diagnostic orphans: Adolescents with alcohol symptoms but no DSM-IV diagnosis. American Journal of Psychiatry, 156, 897-901.

Pollock, N. K., Martin, C. S., \& Langenbucher, J. W. (2000). Diagnostic concordance of DSM-III, DSM-III-R, DSM-IV, and ICD-10 alcohol diagnoses in adolescents. Journal of Studies on Alcohol, 61, 439-446.

Potenza, M. N. (2006). Should addictive disorders include non-substancerelated conditions? Addiction, 101, 142-151.

Proudfoot, H., Baillie, A. J., \& Teesson, M. (2006). The structure of alcohol dependence in the community. Drug and Alcohol Dependence, 81, 21-26.

Robins, L. N. (1989). Diagnostic grammar and assessment: Translating criteria into questions. Psychological Medicine, 19, 57-68.

Robins, L., \& Guze, S. (1970). Establishment of diagnostic validity in psychiatric illness: Its application to schizophrenia. American Journal of Psychiatry, 126, 983-987.

Robinson, T. E., \& Berridge, K. C. (2003). Addiction. Annual Review of Psychology, 54, 25-53.

Room, R., Janca, A., Bennett, L. A., Schmidt, L., \& Sartorius, N. (1996). WHO cross-cultural applicability research on diagnosis and assessment of substance use disorders: An overview of methods and selected results. Addiction, 91, 199-220.

Rush, B. (1787). An inquiry into the effects of ardent spirits on the human body and mind. Philadelphia: Author.

Saha, T. D., Chou, S. P., \& Grant, B. F. (2006). Toward an alcohol use disorder continuum using item response theory: Results from the National Epidemiologic Survey on Alcohol and Related Conditions. Psychological Medicine, 36, 931-941.

Saha, T. D., Stinson, F. S., \& Grant, B. F. (2007). The role of alcohol consumption in future classifications of alcohol use disorders. Drug and Alcohol Dependence, 89, 82-92.

Saunders, J. B. (2006). Substance dependence and non-dependence in the Diagnostic and Statistical Manual of Mental Disorders (DSM) and the International Classification of Diseases (ICD): Can an identical conceptualization be achieved? Addiction, 101, 48-58.

Schuckit, M. A. (1994). Introduction to Section I: Substance-related disorders. In T. A. Widiger, A. J. Frances, H.A. Pincus, M. B. First, R. Ross, \& W. Davis (Eds.), DSM-IV sourcebook (Vol. 1, pp. 5-20).Washington, DC: American Psychiatric Association.

Schuckit, M. A., Daeppen, J. B., Danko, G. P., Tripp, M. L., Smith, T. L., Li, T.-K., et al. (1999). Clinical implications for four drugs of the DSM-IV distinction between substance dependence with and without a physiological component. American Journal of Psychiatry, $156,41-49$

Schuckit, M. A., Danko, G. P., Smith, T. L., Hesselbrock, V., Kramer, J., \& Bucholz, K. (2003). A five-year prospective evaluation of DSM-IV alcohol dependence with and without a physiological component. Alcoholism: Clinical and Experimental Research, 27, 818-825.

Schuckit, M. A., \& Saunders, J. B. (2006). The empirical basis of substance use disorders diagnosis: Research recommendations for the Diagnostic and Statistical Manual of Mental Disorders, fifth edition (DSM-V). Addiction, 101, 170-173.

Schuckit, M. A., Smith, T. L., Daeppan, J. B., Eng, M., Li, T.-K., Hesselbrock, V. M., et al. (1998). Clinical relevance of the distinction between alcohol dependence with and without a physiological component. American Journal of Psychiatry, 155, 733-740.

Schuckit, M. A., Smith, T. L., Danko, G. P., Bucholz, K. K., Reich, T., \& Beirut, L. (2001). Five-year clinical course associated with DSM-IV alcohol abuse or dependence in a large group of men and women. American Journal of Psychiatry, 58, 1084-1090.

Spitzer, R. L., \& Endicott, J. (1978). Medical and mental disorder: Proposed definition and criteria. In R. L. Spitzer \& D. F. Klein (Eds.), Critical issues in psychiatric diagnosis (pp. 15-39). New York: Raven Press.

Spitzer, R. L., \& Wakefield, J. C. (1999). DSM-IV diagnostic criterion for clinical significance: Does it help solve the false positives problem? American Journal of Psychiatry, 156, 1856-1864.

Teesson, M., Lynskey, M. T., Manor, B., \& Baillie, A. (2002). The structure of cannabis dependence in the community. Drug and Alcohol Dependence, 68, 255-262.

Vaillant, G. E. (1983). The natural history of alcoholism. Cambridge, MA: Harvard University Press.

Wakefield, J. C. (1992). Disorder as harmful dysfunction: A conceptual critique of DSM-III-R's definition of mental disorder. Psychological Review, 99, 232-247.

Wakefield, J. C. (1999). Evolutionary versus prototype analyses of the concept of disorder. Journal of Abnormal Psychology, 108, 374-399.

Wakefield, J. C., \& First, M. B. (2003). Clarifying the distinction between 
disorder and nondisorder: Confronting the overdiagnosis problem in DSM-V. In K. A. Phillips, M. B. First, \& H. A. Pincus (Eds.), Advancing DSM: Dilemmas in psychiatric diagnosis (pp. 23-56). Washington, DC: American Psychiatric Association.

Watson, D. (2005). Rethinking the mood and anxiety disorders: A quantitative hierarchical model for DSM-V. Journal of Abnormal Psychology, 114, 522-536.

Widiger, T. A., \& Clark, L. A. (2000). Toward DSM-V and the classification of psychopathology. Psychological Bulletin, 126, 946-963.

Widiger, T. A., \& Samuel, D. B. (2005). Diagnostic categories or dimensions? A question for the Diagnostic and Statistical Manual of Mental Disorders-Fifth Edition. Journal of Abnormal Psychology, 114, 494504
Widiger, T. A., \& Trull, T. J. (2007). Plate tectonics in the classification of personality disorder: Shifting to a dimensional model. American Psychologist, 62, 71-83.

Wise, R. A., \& Bozarth, M. A. (1987). A psychomotor stimulant theory of addiction. Psychological Review, 94, 469-492.

World Health Organization. (1992). International classification of diseases and related health problems (10th ed.). Geneva, Switzerland: Author.

Received February 20, 2007

Revision received February 13, 2008

Accepted February 25, 2008

\section{E-Mail Notification of Your Latest Issue Online!}

Would you like to know when the next issue of your favorite APA journal will be available online? This service is now available to you. Sign up at http://notify.apa.org/ and you will be notified by e-mail when issues of interest to you become available! 